\title{
Estruturas de Governança e Atributos das Transações no Complexo Agroindustrial de Florestas Ribas do Rio Pardo (MS)
}

\author{
Flávio Braga de Almeida Gabriel \\ Universidade Estadual do Oeste do Paraná - Toledo - PR - Brasil \\ ORCID: https://orcid.org/0000-0003-3927-2145 \\ Daniel Amorim Souza Centurião \\ Universidade Estadual do Oeste do Paraná - Toledo - PR - Brasil \\ ORCID: https://orcid.org/0000-0001-8372-6269 \\ Caroline Andressa Welter \\ Universidade Estadual do Oeste do Paraná - Toledo - PR - Brasil \\ ORCID: https://orcid.org/0000-0001-6389-7263 \\ Grazielli Olimpia Viviani Pedroso da Silva \\ Universidade Estadual do Oeste do Paraná - Toledo - PR - Brasil \\ ORCID: https://orcid.org/0000-0002-3635-7883
}

\begin{abstract}
Resumo
Este trabalho consiste em avaliar como os agentes econômicos do complexo agroindustrial de florestas plantadas de Ribas do Rio Pardo - MS se relacionam, a luz da teoria da economia institucional? Para isso, foram adotados os objetivos de identificar quais as estruturas de governança adotadas por este complexo agroindustrial, com base nos atributos das transações, e elencar suas influências no desenvolvimento local. Como metodologia, foi realizada uma pesquisa qualitativa, com informações primárias e secundárias, através da aplicação de questionários mistos semiestruturados, visitas in loco e opinião de especialistas do segmento. Como resultado, evidencia-se uma heterogeneidade quanto às estruturas de governança presentes no complexo, devido principalmente a grande disparidade existente nos atributos das transações, tornando o desenvolvimento local dependente dos elos mais fortes do complexo agroindustrial.
\end{abstract}

Palavras-chave: Desenvolvimento Local. Aglomerações Produtivas. Silvicultura. 


\section{Structures of Governance and Attributes of Transactions in Complex Agroindustrial of Forests in Ribas do Rio Pardo/MS}

\section{Abstract}

This work consists of evaluating how the economic agents of the agroindustrial complex of planted forests in Ribas do Rio Pardo - MS are related, in the light of the theory of institutional economics? To this end, the objectives were adopted to identify which governance structures were adopted by this agro-industrial complex, based on the attributes of the transactions, and to list their influences on local development. As a methodology, a qualitative research was carried out, with primary and secondary information, through the application of mixed semi-structured questionnaires, on-site visits and the opinion of specialists in the segment. As a result, there is a heterogeneity in the governance structures present in the complex, mainly due to the great disparity in the attributes of transactions, making local development dependent on the strongest links in the agro-industrial complex.

Keywords: Local development. Productive agglomeration. Silviculture.

\section{Las Estructuras de Gobernanza y Atributos de las Transacciones en el Complejo Agroindustrial de Bosques de Ribas do Río Pardo/MS \\ Resumen}

Este trabajo consiste en evaluar cómo los agentes económicos del complejo agroindustrial de bosques plantados en Ribas do Rio Pardo - MS están relacionados, a la luz de la teoría de la economía institucional. Con este fin, se adoptaron los objetivos para identificar qué estructuras de gobernanza fueron adoptadas por este complejo agroindustrial, en función de los atributos de las transacciones, y para enumerar sus influencias en el desarrollo local. Como metodología, se realizó una investigación cualitativa, con información primaria y secundaria, mediante la aplicación de cuestionarios semiestructurados mixtos, visitas in situ y la opinión de especialistas en el segmento. Como resultado, existe una heterogeneidad en las estructuras de gobernanza presentes en el complejo, principalmente debido a la gran disparidad en los atributos de las transacciones, lo que hace que el desarrollo local dependa de los vínculos más fuertes en el complejo agroindustrial.

Palabras clave: Desarrollo Local. Establecimientos productivos. Forestales.

\section{Introdução}

As florestas plantadas demonstraram boa participação na economia do estado do Mato Grosso do Sul, ocupando uma área de 392.042 mil hectares em 2010, passando para 487.399 mil hectares em 2011 e para 597.135 mil hectares em 2012, conforme a Associação Brasileira de Produtores de Florestas Plantadas (ABRAF) (2013). O estado do Mato Grosso do Sul em 2007 representava 3,97\% das florestas plantadas do país, passando em 2012 a representar 9,0\%, quase o triplo segundo a ABRAF (2013). Fica evidente o crescimento desta cultura, além de todo um cenário favorável ao seu crescimento e sua importância para o estado.

A região do Bolsão formada pelas microrregiões de Três Lagoas, Paranaíba e Cassilândia, se destaca nesta atividade, sendo responsável por quase toda a produção do estado. Esta região foi constituída formalmente e é objeto de planejamento governamental em suas três esferas, que tem por objetivo a divisão do território do estado em zonas macro, que possibilitem uma gestão produtiva personalizada de cada espaço. 
O município de Ribas do Rio Pardo pela sua localização estratégica, em relação à região do bolsão, se apresenta como segundo maior município na atividade com 99.418 hectares de eucalipto plantados, representando $24,11 \%$ da área de eucalipto da região do bolsão, além de 2.360 hectares de pinus representando $69,07 \%$ área plantada de pinus desta região, ambos para o ano de 2012, segundo dados do projeto Sistema de Informação Geográfica do Agronegócio (SIGA - MS) (2012).

Este município é um importante pólo de florestas e produtos florestais do estado, possuindo áreas plantadas das sete principais empresas produtoras de florestas plantadas de pinus e eucalipto, segundo dados da Associação Sul-MatoGrossense de Produtores e Consumidores de Florestas Plantadas (REFLORE), em 2009. Estas empresas juntas representaram cerca de $70 \%$ das florestas plantadas do estado, somando um montante de 341.179,3 hectares, sem contar ainda com os pequenos proprietários, que somam trinta e duas unidades produtivas no município (REFLORE, 2009). Além disso, conta com um importante pólo de indústrias de beneficiamento de madeira, proveniente de florestas plantadas, com dezesseis serrarias, que realizam o desdobramento de madeira de pinus e trinta empresas produtoras de carvão vegetal.

Estas informações, permitem visualizar o destaque da produção de florestas plantadas no município de Ribas do Rio Pardo, este estudo pretende responder o seguinte questionamento: Como os agentes econômicos do complexo agroindustrial de florestas plantadas deste município se relacionam? Para isso, este trabalho valeu-se da teoria da Nova Economia Institucional (NEI) que permite analisar como ocorrem as transações econômicas deste complexo agroindustrial e identificar fatores impeditivos à ocorrência de desenvolvimento ao longo do tempo, visto que podem estar incorrendo em custos de transações. Na análise econômica proposta pela NEl, o modelo de organização dos agentes econômicos contribui de forma determinante para o modo com que se relacionam e obtém ou não, no mercado, vantagens competitivas.

Dessa forma, o objetivo é identificar qual estrutura de governança é adotada pelos agentes deste complexo agroindustrial e verificar como estas estruturas tem impactado no desenvolvimento local do município. Tais agentes são pouco estudados, com a existência de poucos trabalhos relacionados ao tema, sendo os mais atuais: Chaebo et al. (2009), Fagundes, Schmidt e Rui Neto (2011), Schmidt et al. (2013) e Centurião (2014).

O estudo está dividido em seis seções, que inclui esta breve introdução ao tema, objetivo e importância da pesquisa. Na segunda seção é feita uma revisão de literatura sobre a NEI e na terceira é realizada uma explanação sobre a discussão em torno da definição de complexo agroindustrial e na quarta seção são apresentadas algumas características do município de Ribas do Rio Pardo/MS. A quinta seção apresenta o procedimento metodológico e a sexta seção mostra os resultados encontrados pela pesquisa. Por fim, são apresentadas as considerações finais. 


\section{A Nova Economia Institucional}

A primeira abordagem, que veio a dar origem à NEI ocorreu em 1937 com o texto 'The nature of the firm', de Coase em que as pressuposições neoclássicas começam a ser questionadas. Já nas primeiras páginas, é feito um questionamento contundente ao argumento neoclássico, "Yet, having regard to the fact that if production is regulated by the price movements, production could be carried on without any organization at all, well might we ask, why is there any organization?" (COASE, 1991, p. 2).

Para responder aos devidos questionamentos realizados, a NEI estruturou-se em várias frentes teóricas de estudo I, de forma que cada uma destas tinha por objetivo explicar o comportamento de uma porção diferente de agentes organizados de formas específicas, e a NEI passa a considerar a firma como uma organização coordenada pelos contratos, que são definidos pelos agentes econômicos envolvidos.

Neste trabalho, é adotada a Economia dos Custos de Transação (ECT), que enfoca a forma com que os agentes se organizam para transacionar com eficiência, conforme se apresenta "Transaction cost economics subscribe to the idea that the transaction is the basic unit of analysis and governance is an effort to craft order, thereby to mitigate conflicts and to realize mutual gains" (WILLIAMSON, 2000, p. 599).

Os pressupostos comportamentais de racionalidade limitada e oportunismo são os primeiros aspectos a serem considerados, quando da análise ou estabelecimento de algum tipo de transação entre agentes, uma vez que, balizam o comportamento e as decisões a serem tomadas pelas firmas envolvidas no processo, dependendo dos ganhos e perdas presentes e futuros em que os mesmos são capazes de influenciar.

Para Azevedo (1997), os agentes não possuem habilidade de processar todas as informações necessárias a uma tomada de decisão ideal, como a função de produção neoclássica refletia, esta incapacidade gera em todo o mecanismo de transações do sistema onde o agente encontra-se inserido custos de uso deste sistema, os chamados custos de transação. Para este autor, esses custos não são gerados somente pela função de custos naturais a produção, mas à medida que os agentes conduzem transações entre si e pela falta de coordenação entre eles.

A partir destes indicativos é possível denotar a racionalidade limitada como incerteza das transações e informações imperfeitas, e, portanto, é neste ambiente econômico em que a firma atua, sendo a minimização destes custos realizada pelas formas com que as firmas se arranjam neste ambiente, buscando coordenar as transações e ganhar assim eficiência, conforme Farina (1997).

O oportunismo consiste no reconhecimento de que os agentes buscam o autointeresse (pressuposto neoclássico), no entanto, pode fazê-lo utilizando informações privilegiadas, quebrando contratos para apropriar-se de ganhos

\footnotetext{
${ }^{\text {I }}$ A saber, a NEI se subdivide em duas frentes, uma atuando com um olhar sobre o ambiente institucional, que se desmembram na análise das leis, normas, costumes dentre outros vários tipos de instituições. A segunda trata das estruturas de governança propriamente ditas, analisando os custos de transação e a organização dos agentes, principalmente.
} 
associados à transação, chegando a ferir códigos de ética aceitos pela sociedade, conforme Zylbersztajn (2000).

Desta maneira, incorporando a análise neoclássica, tem-se a possibilidade do agente que gera externalidades negativas em seu mercado por meio de seu comportamento. "(...) All complex contracts are unavoidably incomplete. For this reason, parties will be confronted with the need to adapt to unanticipated disturbances that arise by reasons of gaps, errors and omissions in the original contract." (WILLIAMSON, 2002, p. 174).

Ao mecanismo a ser adotado para que ocorra o processo de coordenação das atividades entre estes diferentes agentes, quando de sua atuação em conjunto, chama-se de estrutura de governança. Com a frequência de ocorrência de transações, os agentes passam a observar as inconsistências nelas envolvidas e a incorporar os riscos às transações vindouras. A fim de evitar novas inconsistências, criam-se 'mecanismos e estruturas de governança' [grifo nosso] para redução dos efeitos de novas inconsistências (AZEVEDO, 1997, p. 71).

Douglas North apresenta a influência institucional na decisão da estrutura de governança pela firma, definindo este ambiente "Institutions are the humanly devised constraints that structure political, economic and social interaction" (NORTH, 1991, p. 97).

Outros aspectos considerados pela firma estão detalhados por Williamson (2002, p.175) abordando que eles carregam importantes efeitos para as transações e, portanto, para a forma de governança adotada: as especificidades de ativos por causarem certa dependência bilateral; as imperfeições de informação por levarem à sequenciais adaptações inadequadas as transação, e por fim, a frequência das transações, por poder impactar diretamente na reputação dos agentes e na sensibilidade de agentes verticalizarem ou não suas estruturas, por este motivo o autor ressalta "(...) transactions should be aligned with appropriate governance structures.". Observam-se as relações existentes entre as características da transação, os tipos de governança e contratos, através do Quadro 1.

Quadro 1 - Relação entre características e formas eficientes de governança

\begin{tabular}{|c|c|c|c|}
\hline \multirow{2}{*}{ Frequência } & \multicolumn{3}{|c|}{ Especificidade dos ativos } \\
\hline & Mercado & Híbrido & Hierarquias \\
\hline Ocasional & $\begin{array}{l}\text { Mercado } \\
\text { Contrato } \\
\text { clássico }\end{array}$ & $\begin{array}{l}\text { Governança trilateral } \\
\text { Contrato neoclássico }\end{array}$ & $\begin{array}{l}\text { Governança trilateral } \\
\text { Contrato neoclássico }\end{array}$ \\
\hline Discreta & $\begin{array}{l}\text { Mercado } \\
\text { Contrato } \\
\text { clássico }\end{array}$ & $\begin{array}{l}\text { Governança trilateral } \\
\text { Contrato neoclássico }\end{array}$ & $\begin{array}{l}\text { Governança unificada } \\
\text { ou bilateral } \\
\text { Contrato neoclássico }\end{array}$ \\
\hline Recorrente & $\begin{array}{l}\text { Mercado } \\
\text { Contrato } \\
\text { clássico }\end{array}$ & $\begin{array}{l}\text { Governança trilateral } \\
\text { Contrato relacional }\end{array}$ & $\begin{array}{l}\text { Governança unificada } \\
\text { Contrato relacional }\end{array}$ \\
\hline
\end{tabular}

Fonte: Adaptado de Williamson (1979).

Para frequência ocasional, discreta e recorrente, com ativos de especificidade baixa, o contrato clássico é usado e recebe proteção da ação de oportunistas e também incentivos através da estrutura de governança mercado. 
Ativos com especificidade intermediária ou alta, com frequência ocasional ou discreta, têm um aumento da ação oportunista.

O estabelecimento de um compromisso confiável entre os agentes está diretamente associado a evitar um comportamento oportunista por parte dos agentes. "Como a transação tem a perspectiva de continuidade, uma atitude oportunista - desde que observável - tem como penalidade a interrupção da relação, cujo custo é dado pelo valor presente descontado dos ganhos futuros derivados da transação" (AZEVEDO, 1997, p. 90). Quando há uma quebra na relação de confiança estabelecida pela repetição de determinada transação, passa a existir um custo mais elevado associado ao risco de comportamento oportunista por parte dos agentes. Com relação à incerteza, trata-se de um aspecto de mais difícil controle, pois diferentemente do risco, não pode ser mensurada.

Para Azevedo (1997, p. 99), conforme a firma avança no sentido de verticalizar suas atividades a mesma "perde em incentivo e ganha em controle". Conforme se amplia a especificidade dos ativos, há também uma ampliação da necessidade do poder de controle sobre as transações, buscando, portanto, evitar atitudes oportunistas por parte do mercado.

Desta maneira, o grande desafio da firma, das instituições e organizações é a determinação de uma estrutura de governança, única, ideal a ponto de promover coordenação e eficiência ao sistema econômico em questão. Conforme ressalta Williamson (2002, p. 175) "The challenge is to enunciate the relevant attributes for describing governance structures and thereafter to align different kinds of transactions with discrete modes of governance in an economizing way."

A NEI e, em especial, a ECT apresentam-se estritamente aplicáveis ao agronegócio. Desde sua organização de forma sistêmica, o agronegócio passou a se utilizar de ferramentas que pudessem aperfeiçoar seus processos de produção, transformação, comercialização e distribuição de bens e minimizar os custos a estes processos relacionados, a percepção de produção rural foi em muito ampliada e especializada.

A certificação florestal é um claro exemplo de especialização produtiva e de avanço no sentido da promoção da qualidade e normatização, que envolve não somente a empresa, mas toda a sua cadeia de suprimentos e também a população do local onde a empresa encontra-se instalada, conforme apresenta Giordano (2009, p. 171) "It should encompass a group of actions that start with the awareness of the problem, passes through technical standardization, and advances toward the operational, administrative and recording procedures and also relationship with society".

Toda a organização dos agentes em um sistema necessita de coordenação de modo a garantir a eficiência, e deste modo de gerar vantagens mútuas aos agentes e retornos à sociedade. Para Farina (1999) o processo de coordenação provém, portanto, de uma construção dos agentes econômicos envolvidos na transação, de forma que não é uma característica intrínseca dos sistemas de produção, a chamada "tecnologia" produtiva dita, mas não explicada na economia neoclássica. 


\section{A NEI e o Desenvolvimento Local}

O conceito central para a análise do desenvolvimento econômico a partir da NEI está na compreensão das instituições, como sendo as formais constituídas por leis e ações constitutivas impostas formalmente pelo governo ou outros agentes da economia ou aquelas informais como normas, códigos de conduta, hábitos e costumes formados e chancelados pelos próprios agentes econômicos e sociais, são esses os dois tipos básicos de instituições conforme North (1990).

Exemplo da existência e mudanças institucionais dentro do setor agroindustrial é apresentado por (COSTA, 2007, p. 65) ao afirmar que propriedade rural não era tratada como um empreendimento, sendo vista como um "ramo especial, tradicional, com suas próprias regras e estrutura paternalista”. Diante deste retrato, a nova gestão agroindustrial destaca-se principalmente pelas mudanças nas técnicas de produção e de gestão das propriedades, que perpassam pelas inovações tecnológicas e pela inserção da tecnologia na produção.

$\mathrm{Na}$ análise dos complexos agroindustriais como conjunto empresarial, neste caso, agroindustrial, Zylbersztajn e Scare (2003) propõem a necessidade de coordenação e gerenciamento destes complexos. Essa necessidade constitui-se no alinhamento entre a estrutura de governança e os agentes do complexo, de forma a promover externalidades positivas à região e mitigar custos de transação no complexo.

Diante desta percepção sistêmica, dar-se-á, a devida importância para a interação entre as estruturas de governança e sua relação com os players de cada um dos elos deste complexo, possibilitando assim um gerenciamento virtuoso no sentido da promoção do desenvolvimento. Para North $(2003$, p. 1) "The continuous interaction between institutions and organizations in the economic setting of scarcity and hence competition is the key to institutional change."

Essas mudanças institucionais ao olhar de North (1990) seriam capazes de prover um avanço institucional que elevaria o desempenho econômico ao longo do tempo. O avanço das ideias de North e seu alinhamento às teorias do desenvolvimento, como a evolucionária, adicionaram ideias proeminentes na análise local como aponta Arend et al. (2012), afirmando que o marco institucional organizado importa "pois as inovações provêem de determinados arranjos institucionais", e são promotoras do desenvolvimento.

Na esfera regional, Haddad (1999) insere como premissas do processo de desenvolvimento de uma região: a sincronia intersetorial e territorial do crescimento; e a percepção coletiva de pertencer à região, ambos considerados fatores endógenos de composição do "sistema produtivo regional competitivamente dinâmico" [grifo nosso] que irá promover o desenvolvimento e a integração desta região às demais. Este argumento complementa a noção tratada por Arend et al. (2012) e North (1990) do papel institucional na promoção do desenvolvimento.

A falta de sensação coletiva de pertencer é tratada de forma bem conveniente a este debate por Santos (2003), interpretando o fato da inserção do capital em um território e destacando o processo de (re)dinamização do local e de sua inserção em uma esfera mais ampla. 
Seguindo, Santos (2003) expõe três dimensões do capital necessárias ao empreendimento agrícola, sendo eles, capital vivo, capital fixo "dormente" [grifo do autor] e capital variável, fazendo a ressalva de que não é necessariamente o papel do capital produtivo promover o desempenho econômico, mas que o capital vivo sim, assume sempre uma postura promotora da geração de infraestrutura. Finaliza apontando que o estado tende a assumir uma ideologia estatística do crescimento, fornecendo recursos extras para os territórios, em que o capital se reproduz e se acumula mais facilmente, desfavorecendo o capital vivo dos territórios.

Dentro desta concepção, a escolha do local e a implantação efetiva de uma unidade econômica, pressupõem o entendimento da infraestrutura - inclusive institucional - disponível e da possível geração de ampliação de níveis de renda, produção e emprego, acima do crescimento da população, sem que necessariamente, haja no local, um processo de desenvolvimento econômico e social, de acordo com Haddad (1999).

A inserção de um complexo agroindustrial pode gerar um processo unicamente de crescimento econômico (espúrio). Para que ocorra a atração à inserção de um complexo no local, a região precisa ter, conforme Haddad (1999, p. 8), "a capacidade (...) de atrair recursos nacionais e internacionais, públicos e privados, através de diferentes modalidades (...)".

\section{O contexto do município de Ribas do Rio Pardo}

Ribas do Rio Pardo destaca-se no estado de Mato Grosso do Sul como produtor de florestas, apresenta solo e clima propícios ao desenvolvimento desta atividade, bem como grandes áreas de antigas pastagens já de baixa produtividade, com disponibilidade para inserção de uma nova cultura com maior retorno. Encontra-se entre os municípios destinados para projetos florestais no Zoneamento Ecológico-Econômico de MS (ZEE - MS) (MATO GROSSO DO SUL, 2009).

Pelo Censo agropecuário de 2006 nota-se que o município possuía naquele ano apenas 31.367 hectares de florestas plantadas, enquanto contava com 58.427 hectares de pastagens plantadas degradas e outros 1,3 milhão de hectares de pastagens plantadas em boas condições, revelando assim a extensão da disponibilidade de terras para o avanço de florestas plantadas.

A lavoura permanente bastante limitada o município contava em 2006 com apenas 5 estabelecimentos dedicados as culturas de café laranja e banana. Já as lavouras temporárias na produção de milho, mandioca, soja, cana de açúcar, sendo as duas últimas as mais expressivas em valores da produção e na quantidade de hectares produzidos. Na pecuária os destaques eram a criação de bovinos para corte e leite, sendo o primeiro caso mais expressivo, 1,23 milhões de cabeças era o total do rebanho (IBGE, 2006). A predominância absoluta de proprietários de terra, sendo assim como o pessoal ocupado de sexo masculino em esmagadora maioria.

É possível notar (Figura 1) a baixa diversificação agrícola, e forte crescimento da produção de florestas comerciais com potencial de avanço sobre as áreas de pastagens. Assim, o município apresenta condições favoráveis para o crescimento de um complexo agroindustrial constituído a partir de produção florestal por 
possuir as características acima evidenciadas e também por seu posicionamento estratégico com relação aos demais municípios do estado que se desenvolveram na atividade, como por exemplo, Três Lagoas

Figura 1 - Áreas produtivas plantadas em Ribas do Rio Pardo - MS

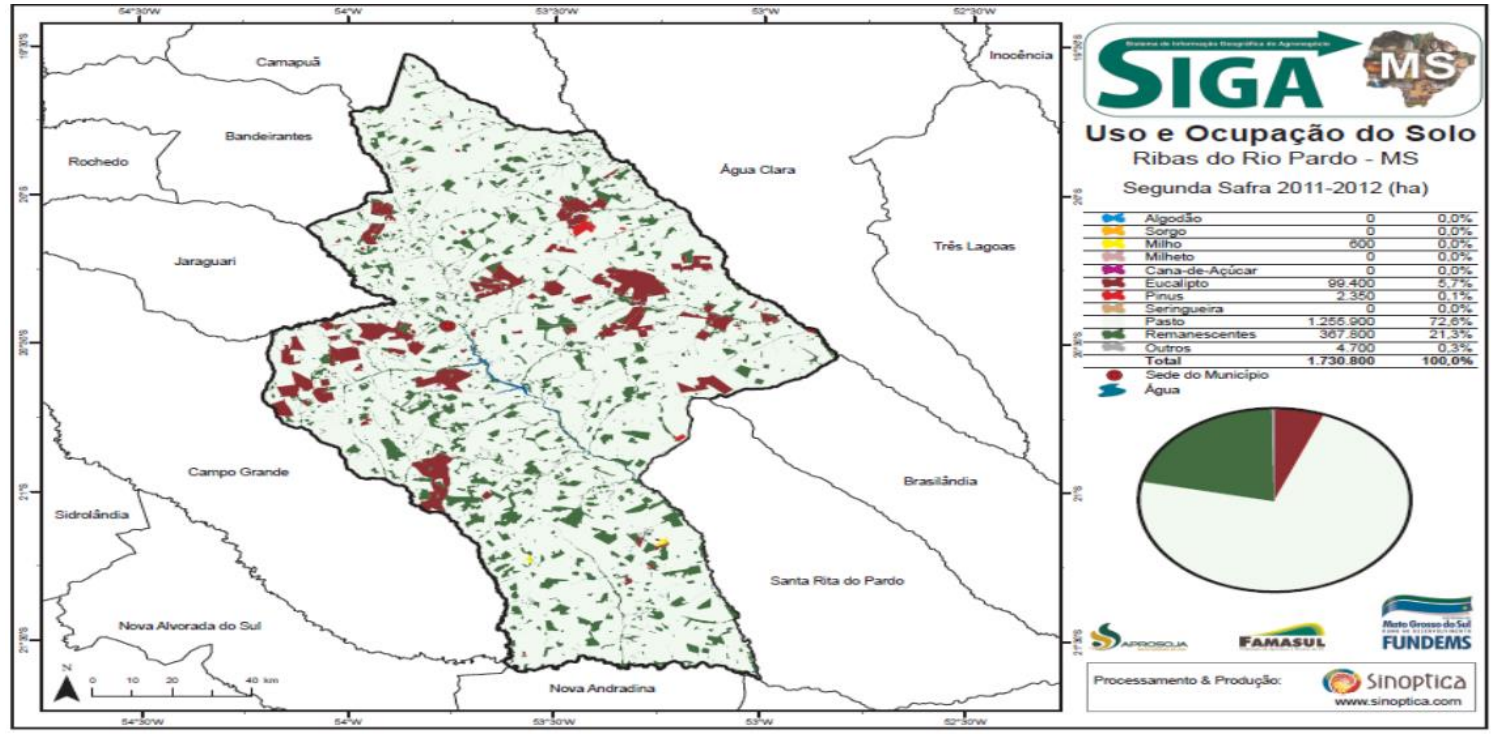

Fonte: Projeto SIGA MS (2011-2012).

O município assume uma posição estratégica próximo as duas maiores plantas produtivas de celulose de fibra curta branqueada, sendo estas empresas indutoras na região. Fíbria e a Eldorado, que se encontram instaladas em Três Lagoas, a $229 \mathrm{~km}$ de Ribas do Rio Pardo. O município possui atividades beneficiadoras de madeira bruta e com mercado consumidor estabelecido, tanto no próprio município como dentro e fora do estado.

Dentre estas atividades, de acordo com Centurião (2014), destacam-se serrarias, carvoarias, laminadoras, plantas industriais de produção de artefatos e utilidades de madeira desdobrada e, indústrias consumidoras de madeira para energia. Todo este aparelho produtivo é caracterizado como complexo agroindustrial de florestas plantadas de pinus e eucalipto de Ribas do Rio Pardo, que vêm moldando a dinâmica da economia local, deixando de ser uma atividade essencialmente agrícola, e evoluindo para um intenso processo industrial.

\section{Metodologia}

O trabalho constituiu-se em uma pesquisa bibliográfica e qualitativa segundo as definições apresentadas por Vergara (2005). Para Marconi e Lakatos (2009), a pesquisa qualitativa caracteriza-se por depender da dedução ou de inferências do contexto geral para o particular, sendo relevante no processo de formulação de novas teorias e descrevendo de forma completa o fenômeno analisado.

Para responder qual estrutura de governança é adotada pelos agentes do complexo agroindustrial de florestas plantadas de pinus e eucalipto de Ribas do Rio Pardo, primeiro foi realizado um esboço das transações e inter-relações das 
atividades, a partir do mapeamento deste complexo agroindustrial, levantando seus agentes e caracterizando-o como tal. O mapeamento seguiu uma adaptação da metodologia desenvolvida, publicada e aplicada pelo Centro de Conhecimento em Agronegócios (grupo PENSA), que pode ser verificada na íntegra em Centurião (2014).

Foram feitas entrevistas semiestruturadas com os principais agentes identificados totalizando 12 entrevistas em três serrarias, três produtores, três fornecedores de insumos e implementos e três entidades representativas, a fim de constituir uma caracterização básica das transações. Ainda nesta etapa foi realizada uma consulta a quatro especialistas que realizaram considerações acerca de como estas transações tem impactado no desenvolvimento local do município.

De posse das informações das entrevistas, foi possível analisar como ocorrem as transações entre os agentes do complexo sob o ponto de vista da NEI, em especial na ECT, envolvendo os conceitos de assimetria de informações, racionalidade limitada, oportunismo, frequência das transações, especificidade dos ativos, entre outros. Isso possibilitou a construção de um esboço de como os agentes se organizam e assim, possibilitou indicar a estrutura de governança adotada por eles.

\section{Resultados e Discussões}

O mapeamento do complexo agroindustrial encontra-se apresentado na Figura 1. As etapas destacadas na cor azul não estão localizadas fisicamente no município, porém apresentam grande importância e representatividade para entendimento do fluxo, pois se trata de etapas indutoras de todo o processo. Além disso, pela falta de planejamento regional a partir destes elos ocorreram as maiores assimetrias. Quando os projetos de investimentos de grandes plantas foram anunciados, a falta de informações adequadas por parte dos agentes locais gerou uma grande especulação em termos de renda das terras e também com relação aos plantios, para transação com estas plantas.

O que ocorreu foi que as plantas introduziram um modelo produtivo extremamente verticalizado, consumindo insumos, em sua maioria, produzidos por elas mesmas, e muitos plantios de médios produtores tiveram que ser direcionados a outros mercados a preços menores. Com relação às terras, ocorreu justamente o oposto, pois as grandes plantas arrendaram muitas terras para grandes plantios, elevando bruscamente os preços da terra no local.

As atividades "antes da porteira", nos elos de pequenos varejos e serviços no município, ainda são incipientes e frágeis, dispõe de um conjunto limitado de produtos e serviços, e atendem aos agentes adiante de sua posição no complexo de forma primária ou somente em necessidades de extrema urgência.

As negociações são conduzidas principalmente pelo poder de barganha das serrarias e produtores que detêm melhores informações com relação às especificações de produto, e também, acesso e possibilidade de compra de ativos, mais qualificados e específicos em mercados fora das fronteiras do município. Estas características se transferem rapidamente para a relação de preços dos produtos e dos serviços locais. 
Assim, o varejo de insumos e o segmento de serviços adotam uma estrutura de governança de mercado, diante das transações com produtores de florestas e serrarias principalmente. As transações ocorrem baseadas principalmente na urgência, com baixa frequência, ativos de baixa especificidade, sem contratos e em alguns casos, com relações até mesmo informais, sem a utilização de notas fiscais ou documentos que registrem estas transações.

Figura 2 - Mapeamento do complexo agroindustrial em Ribas do Rio Pardo

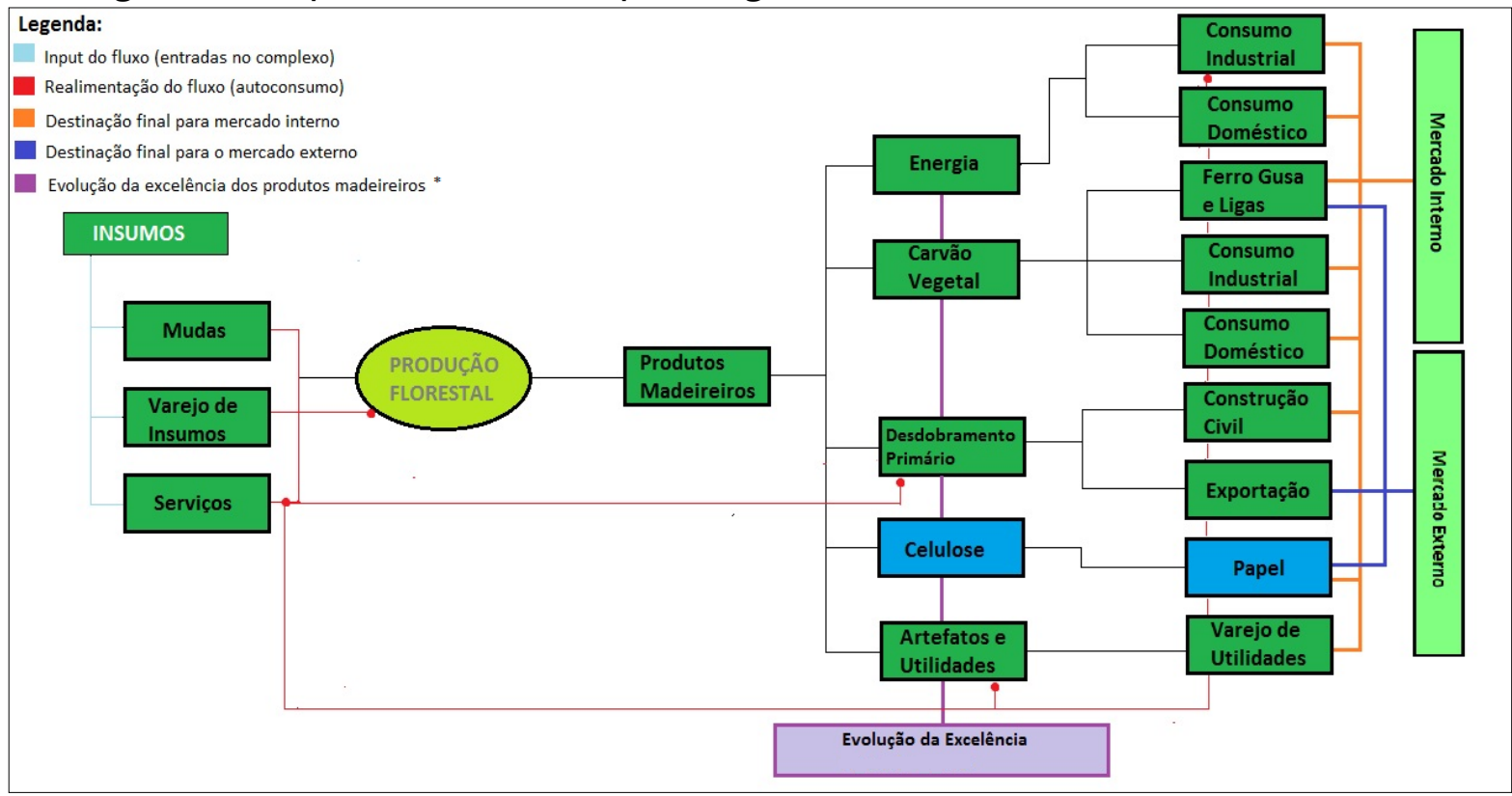

Fonte: Resultados da pesquisa.

Neste sentido, torna se evidente a limitação nos encadeamentos proposta por Haddad (1999), ao apontá-lo como um dos fatores endógenos para a promoção do desenvolvimento local, à medida que os agentes produtores do município apresentam esta fragilidade de consumo local.

Cabe destacar principalmente a falta do senso de pertença, conforme Santos (2003), em ambas as partes desta transação, dos compradores, por preferirem buscar os produtos em outros municípios e, por entenderem os produtos locais como de qualidade inferior com preços possivelmente inflados. $\mathrm{E}$ dos pequenos varejos e serviços por não adotarem um posicionamento mais adequado de parceria e gestão, assumindo assim uma reputação de comodismo diante do mercado local.

Os viveiros de mudas são uma exceção no elo "antes da porteira", pois acompanharam a evolução das necessidades do seu mercado. Dispõe de produtos que atendem os produtores de florestas, principalmente de médio porte e, até mesmo conseguem manter relações com grandes produtores, fora do município, fornecendo com regularidade e com produtos de boa qualidade, de acordo com os entrevistados.

Este grupo apresenta algumas evidências claras de maior maturidade no quesito coordenação, pois possuem produtos voltados para o atendimento da necessidade dos produtores, parcerias e mercados bem definidos, e conseguem, mesmo sendo empresas locais, estabelecer vantagens competitivas em relação ao mercado estadual, principalmente pela proximidade de seus principais 
consumidores, representando assim, uma especificidade locacional. Além disso, possuem relações contratuais de médio e longo prazo, com frequência considerável e, alguns detêm tecnologias de clonagem que tornam seus ativos mais específicos.

Os viveiros costumam assumir bem o transporte e entrega das mudas aos produtores, por estabelecerem uma relação próxima com os mesmos, e por realizarem um alinhamento com relação às especificações, modo de entrega, formas de pagamento e recebimento, homogênea e mutuamente positivas. Estes fatos indicam que são pequenas as assimetrias de informação nestas transações. De modo geral, os viveiros aparentam adotar uma estrutura de governança do tipo mista ou híbrida, sendo uma forma intermediária entre hierarquias e mercados, conforme aponta Williamson (1979).

Os serviços de transporte e armazenagem são um ponto crítico, apontado principalmente pelos produtores de florestas. Este fato é atribuído à irregularidade da qualidade dos serviços prestados e em vezes pela ineficiência e gastos extras gerados por este elo do complexo. Pelas respostas observadas, há indícios fortes de ação oportunista por parte dos prestadores de serviço individuais de transporte, pois atuam na formação de preço diante da necessidade do consumidor, atribuindo a transação, elevados custos e incertezas, conforme Coase (1991). Diante deste cenário, os agentes deste elo aparentam atuar em uma estrutura de governança muito próxima a de mercado.

$\mathrm{Na}$ etapa da produção florestal, tem se os produtores de pequeno, médio e grande porte que são analisados separadamente. Os produtores de grande porte são o elo do complexo mais bem estruturado e organizado no município. A produção é bastante concentrada, principalmente devido ao avanço em qualidade e tecnologia dos produtores, que ganharam, no decorrer destes últimos anos, uma grande fatia de mercado de produção de florestas no estado. Estes produtores trabalham com um volume grande de colaboradores, possuem complexos processos de operação e certificação por grandes certificadoras nacionais e internacionais. O fato de maior maturidade e domínio das relações de comercialização por estes produtores deve-se também ao fato de ser o elo mais antigo do complexo, bem como a origem dele.

Em muitos casos, os produtores têm assumido as etapas de apoio, adquirindo frotas de transporte e espaços de armazenagem próprios, o mesmo ocorre com os serviços de alimentação, hospedagem e reparação. Os casos em que não podem ser assumidos integralmente são contratados empresas e profissionais de outros municípios ou estados, buscando principalmente evitar a ação oportunista, destacada anteriormente no caso dos transportes. Diante destas considerações torna-se aparente a verticalização e a participação no complexo com uma estrutura de governança hierárquica. Deste modo, conforme Azevedo (1997) aumenta-se o controle sobre a atividade desempenhada por este elo.

Ao tratar estes serviços de apoio de forma verticalizada, o elo produtor acarreta ao local e ao complexo, o que é classificado por Haddad (1999), de vantagem competitiva espúria, que ocorre quando as empresas contratadas, ou os serviços assumidos não geram a participação e o fomento de empreendimentos locais, e assim, assumem somente uma atividade de exploração. Esta por sua vez, garante apenas a manutenção da atividade principal de produção florestal, e não gera quase nenhum benefício ao local, além do aparente crescimento econômico, o 
que não garante por si só, uma situação de desenvolvimento local sustentado, diante do argumento apresentado por Santos (2003).

Estes produtores possuem relações contratuais bem estabelecidas, uma atuação que chega a produtos para exportação, em alguns casos. Detém maior volume de informações e, absorvem um grande volume de informações de seus mercados fornecedores e de clientes. Além disso, existe elevada frequência de transações, o que garante a eles uma especificidade inclusive de marca, tornando seus produtos referências no mercado estadual e em alguns casos, no mercado nacional.

Os produtores de médio porte possuem uma fatia bem menor de mercado, são ainda pouco especializados e tem buscado avançar em termos de tecnologia de produção. Sua produção é geralmente destinada ao desdobramento de menor valor agregado, como carvão e lenha, para abastecimento do mercado doméstico e de pequenas fábricas, ou chegando até a fornecer para serrarias ou para o tratamento de madeira.

É evidente o comportamento relacionado à gestão da propriedade, como o "antigo" perfil de gestor, como apresentado por Costa (2007), com um nível baixíssimo de controle administrativo. Acabam incorrendo em relações oportunistas principalmente por parte das serrarias, e ficam de certa forma, a margem do mercado, principalmente em relação a preços, por não possuírem muitas alternativas de transação, a não serem as desenvolvidas no mercado local, ou em pequenos mercados próximos.

Além disso, sua tecnologia de produção é geralmente inferior e de produtividade muito menor a dos grandes produtores, o que torna seus ativos bastante comuns e apresentam dificuldades em assumir o transporte da produção. Assim, estes agentes aparentam atuar em um modelo de estrutura de governança próxima a de mercado.

Os produtores de pequeno porte apresentam comportamento bastante próximo a dos médios produtores, diferindo em dois quesitos, a tecnologia de produção e manejo que é muito artesanal e, a frequência das transações que são ainda menores. Desta forma operam plenamente em uma estrutura de governança de mercado, não havendo inclusive um planejamento antecipado quanto à destinação da produção.

As serrarias e carvoarias são importantes agentes do elo "depois da porteira". As carvoarias estão localizadas em sua totalidade dentro das fazendas produtoras de florestas ou em suas adjacências, tendo sua produção destinada ao mercado interno, atendendo ao consumo doméstico de carvão vegetal, por meio de pequenos revendedores como mercados, mercearias, conveniências e até mesmo vendedores autônomos. Atendem, também, pequenas fábricas que necessitam deste insumo em sua produção.

Além disso, a produção de carvão no município tem uma segunda destinação, de maior importância e rentabilidade, que é a comercialização como matéria prima para a produção de ferro gusa e ligas, realizada no município, principalmente entre as carvoarias e médios produtores de florestas, também produtores de carvão em alguns casos, com a Vetorial Siderurgia, que possui uma planta produtiva instalada em Ribas do Rio Pardo. 
A produção destinada à comercialização de varejo assume geralmente características informais, os preços estão sujeitos à especulação dos varejistas que entregam os produtos ao consumidor final, não existe o estabelecimento de contratos e a frequência se baseia na disponibilidade de carvão para atendimento a esta fatia do mercado. Trata-se de um ativo sem nenhuma especificidade, quase uma commodity. No entanto, existe um movimento por parte das organizações, principalmente do sindicato de produtores, pela melhoria da qualidade em termos de governança e da especificidade dos produtos.

Normalmente, os produtores de médio e pequeno porte destinam parte ou toda a sua produção de madeira para desdobramento em forma de carvão, por ser um ativo que exige baixas especificações em termos de qualidade e, assim, as carvoarias que não são integradas em fazendas produtoras acabam sendo um mercado para estes produtores.

Esse mercado normalmente se dá de maneira informal, onde ambos os lados possuem um elevado nível de assimetria de informações, principalmente quanto às necessidades do mercado final, e por vezes acabam produzindo em níveis superiores a esta necessidade, o que provoca uma oscilação constante no preço do carvão nos varejos e também uma disponibilidade de produtos sazonal.

Para o caso das carvoarias, há evidências de heterogeneidade para estrutura de governança adotada, no primeiro caso, com a produção para o consumo doméstico, aparenta uma forma de mercado. Já no segundo caso, demonstra características da forma híbrida, principalmente pela transação com agentes de grande porte como indústrias e siderúrgicas. O terceiro caso, relacionado a transações com os médios produtores de florestas, que aparenta estar bastante próxima a uma estrutura de governança mercado.

As serrarias estão localizadas em sua maioria no perímetro urbano do município, realizam a secagem e desdobramento de madeira em produtos que, em quase sua totalidade, atendem ao mercado da construção civil. Em alguns casos, as serrarias por meio de um intermediário comercial, realizam a exportação de produtos de maior valor agregado, por atender a especificações do mercado internacional, mais especificamente em um caso observado.

O processo de desdobramento realizado é feito de forma bastante tradicional, sem a incorporação de novas técnicas nem do aproveitamento de matérias primas diversas, com a disponibilização de produtos serrados de valor agregado ainda bastante baixo, com o agravante da não adaptação tecnológica para o desdobramento do eucalipto. Nota-se então, ativos de especificidade baixa, porém com uma frequência considerável, principalmente dado ao aquecimento da construção civil nos últimos anos.

Os níveis de controles administrativos são baixos e com relação à estrutura de governança, as de menor porte, aparentam atuar mais próximas ao mercado e as mais estruturadas, que são maioria, em um formato mais próximo de estruturas híbridas. Vale um destaque especial, para a fragilidade com relação à utilização de contratos e salvaguardas, por atuarem em um mercado consumidor muito segmentado e, em muitas vezes, diretamente com o consumidor final.

Existe apenas uma planta fabril que realiza o desdobramento de toras de madeira em utensílios domésticos e utilidades, porém, esta planta segue a mesma linha de incerteza das serrarias, pois possui um baixo nível de profissionalização e 
um grau de tecnologia inapto para o desdobramento de madeira de eucalipto. Sua produção tem um alcance estadual em maior grau. Atua mais no sentido de transações por reputação, produzindo para intermediários, que colocam seus produtos no mercado, com marcas próprias.

Diante deste cenário, a atuação em termos de estruturas de governança se configura no sentido de uma estrutura de mercado, com uma frequência de transações equacionada pela demanda do mercado de utensílios, baixa especificidade nos ativos e, controles administrativos precários.

Utilizando o Quadro 1, de classificação de estruturas de governança e com base na análise dos resultados apresentada, foi realizada uma adaptação da análise de Williamson (1991) de modo a classificar isoladamente as atividades e por fim identificar a estrutura de governança predominante ao complexo agroindustrial em questão, conforme é apresentado na Tabela 1.

No que tange a governança de mercado, encontra-se um grande grupo de atividades que compõe o complexo, boa parte localizada "antes da porteira" e "dentro da porteira", com exceção das pequenas carvoarias. Nota-se que atuam de forma bastante semelhante ao proposto pela teoria, no que tange a estrutura de governança adotada, apresentando uma grande fragilidade com relação à especificidade de ativos e em certa medida com relação aos controles administrativos.

Os casos observados de maiores assimetrias de informações e, principalmente, da potencial ocorrência de ações oportunistas, são em sua maioria de transações entre estruturas de governança de mercado para com estruturas de governança mais complexas, no caso, estruturas híbridas em maioria. Essas imperfeições são agravadas à medida que os atributos observados se tornam mais díspares entre os agentes do complexo.

As serrarias enquadram-se muito bem nas formas híbridas, com controles administrativos ainda moderados, porém não ausentes. Isto se torna perceptível, por exemplo, nas relações com o comércio local, na falta de adaptação com relação ao desdobramento de eucalipto, dado que esta tecnologia já poderia ter sido desenvolvida, há muitos anos no complexo, por esta atividade. As grandes carvoarias e viveiros de mudas enquadram-se bem nas características presentes na estrutura híbrida, porém vale um destaque para os viveiros, que notadamente apresentam um elevado grau de especificidade. Por fim, os grandes produtores de florestas e as plantas localizadas fora do município também se enquadram bem com as características de hierarquias. 
Tabela 1 - Estruturas de governança presentes no complexo agroindustrial de Ribas do Rio Pardo/MS

\begin{tabular}{|c|c|c|c|c|}
\hline $\begin{array}{l}\text { Estruturas de } \\
\text { Governança }\end{array}$ & Agentes & Frequência & $\begin{array}{c}\text { Especificidade } \\
\text { de ativos }\end{array}$ & $\begin{array}{c}\text { Controles } \\
\text { Administrativos }\end{array}$ \\
\hline \multirow{5}{*}{ Mercado } & Serviços & - & 0 & 0 \\
\hline & $\begin{array}{l}\text { Varejo de } \\
\text { insumos }\end{array}$ & - & 0 & - \\
\hline & $\begin{array}{l}\text { Pequenos } \\
\text { produtores }\end{array}$ & - & 0 & 0 \\
\hline & $\begin{array}{l}\text { Pequenas } \\
\text { carvoarias }\end{array}$ & - & 0 & - \\
\hline & $\begin{array}{c}\text { Produção de } \\
\text { utilidades }\end{array}$ & - & - & - \\
\hline \multirow{3}{*}{ Híbrida } & Serrarias & + & + & - \\
\hline & $\begin{array}{l}\text { Grandes } \\
\text { Carvoarias }\end{array}$ & + & + & + \\
\hline & $\begin{array}{c}\text { Viveiros de } \\
\text { mudas }\end{array}$ & + & ++ & + \\
\hline \multirow{3}{*}{ Hierarquias } & $\begin{array}{l}\text { Grandes } \\
\text { produtores }\end{array}$ & ++ & ++ & ++ \\
\hline & $\begin{array}{c}\text { Plantas } \\
\text { industriais }\end{array}$ & & & \\
\hline & $\begin{array}{c}\text { (fora do } \\
\text { município) }\end{array}$ & ++ & ++ & ++ \\
\hline
\end{tabular}

Nota: ++ = forte; + = moderado; - = mínimo; 0 = ausente.

Fonte: Adaptado de Williamson (1991).

É possível perceber uma heterogeneidade em termos de estruturas de governança no complexo. Esta heterogeneidade tem impacto direto na coordenação destes agentes, reduzindo assim a sua eficiência enquanto complexo. Tal fato fragiliza ainda mais os elos com menor força, posicionados em estruturas de mercado e privilegia, em certa medida, as estruturas hierárquicas que possuem maior controle de sua atividade.

O complexo ainda não atingiu um nível de coordenação entre as estruturas adotadas, conforme proposto por Farina (1999), nem um nível adequado de engajamento e ligação entre os agentes, sendo a individualidade e as ações de curto prazo uma realidade, isso pode ser confirmado pela intensidade de diferenças entre as estruturas de governança aparentemente adotadas.

\section{Considerações finais}

Dado o objetivo de identificar a estrutura de governança que é adotada pelos agentes deste complexo agroindustrial e verificar como estas estruturas têm impactado no desenvolvimento local do município, de forma a responder como estes agentes se relacionam, verifica-se que este foi cumprido a partir do enquadramento realizado por cada um dos elos do complexo, da especificação de 
uma estrutura de governança híbrida, ressaltando heterogeneidades que parecem ser a certa medida punitivas ao desenvolvimento local.

As características e fluxos do complexo agroindustrial de florestas plantadas em Ribas do Rio Pardo permitem uma rápida observação com relação à simplicidade das atividades e produtos gerados que, de uma forma geral, apresentam baixo grau de tecnologia, pouco encadeamento efetivo entre os agentes, ativos pouco específicos e um potencial de atividade geradora de desenvolvimento econômico bastante limitado para o município, exceto por alguns elos que possuem maior dinamismo.

A interação entre produtores de florestas e viveiros no município valeria a dedicação de um trabalho, principalmente com relação aos médios produtores de florestas, pois os grandes costumam absorver este elo da cadeia, verticalizando sua atividade e desenvolvem suas próprias mudas, por questões de custos da atividade e de custos inerentes à especificidade do ativo, por meio da reprodução e melhoramento genético em quantidade muito elevada e com um padrão de qualidade muito alto, devido ao rigor do seu processo produtivo já certificado, em alguns casos.

A heterogeneidade entre as estruturas de governança é conferida pelas grandes disparidades nos atributos das transações observados. As estruturas de maior complexidade acabam não criando, ou criando uma relação de dependência fraca com as atividades de elos do complexo que se desenvolvem localmente. Estas atividades, portanto, passam a sofrer um efeito punitivo, por não possuir capacidade de absorção das externalidades positivas a serem geradas por estas transações. Neste sentido, o desenvolvimento local, torna-se frágil, dependente de atividades indutoras ou de elos mais fortes, que possuem baixa vinculação com o local.

As principais limitações da pesquisa foram a disponibilidade de dados locais e também o acesso aos empresários para a realização das entrevistas semiestruturadas. Algumas sugestões para trabalhos posteriores são o detalhamento de cada um destes elos do complexo e a análise de políticas existentes ou de possíveis propostas que direcionem 0 processo de desenvolvimento do complexo e do local.

\section{REFERÊNCIAS}

ABRAF - ASSOCIAÇÃO BRASILEIRA DE PRODUTORES DE FLORESTAS PLANTADAS. Anuário Estatístico. Brasília: ABRAF. 2013.

ARAÚJO, N. B.; WEDEKIN, I.; PINAZZA, L. A. Complexo agroindustrial - o Agrobusiness Brasileiro. São Paulo: AGROCERES. 1990.

AREND, M.; CARIO, S. A. F.; ENDERLE, R. A. Instituições, inovações e desenvolvimento econômico. Pesquisa e Debate, São Paulo, v. 23, p. 110-113, Novembro 2012. 
AZEVEDO, P. F. Antecedentes - Coase e os anos 30: o redirecionamento do enfoque. In: FARINA, E. M. M. Q.; AZEVEDO, P. F.; SAES, M. S. M. Competitividade: Mercado, Estado e Organizações. São Paulo: Singular, 1997. Cap. Parte I.

CENTURIÃO, D. A. S. Mapeamento dos Agentes do Complexo Agroindustrial de florestas plantadas de pinus e eucalipto do município de Ribas Pardo em Mato Grosso do Sul. 2014. 71f. Trabalho de Conclusão de Curso (Graduação) Universidade Federal do Mato Grosso do Sul, Mato Grosso do Sul, 2014.

CHAEBO, G.; CAMPEÃO, P.; KODAMA, A.; SANTOS, A. B.; NORILLER, R. M. Silvicultura em Mato Grosso do Sul: desafios e perspectivas a formulação de um arranjo produtivo local. In: Congresso da Sociedade Brasileira de Economia, Administração e Sociologia Rural - SOBER, 48, 2009, Campo Grande. Anais... Disponível em: <http://www.sober.org.br/palestra/15/1156.pdf>. Acesso em: 21 out. 2013.

COASE, R. H. The Nature of the Firm. In: WILLIAMSON, O.; WINTER, S. G. The nature of the firm. New York: Oxford Univesity Press, 1991. p. 17.

COSTA, A. J. O poder da agricultura empresarial. São Paulo: Saraiva, 2007.

FAGUNDES, M. B. B.; SCHMIDT, V.; RUI NETO, A. Competitividade do Sistema Agroindustrial da Silvicultura no Mato Grosso do Sul: um enfoque sobre as florestas plantadas de eucalipto. In: Congresso da Sociedade Brasileira de Economia, Administração e Sociologia Rural - SOBER, 49, 2011, Belo Horizonte. Anais... Disponível em: <http://www.sober.org.br/>. Acesso em: 11 jun. 2012.

FARINA. E. M. M. Q. Competitividade e coordenação de sistemas agroindustriais: um ensaio conceitual. Gestão e Produção, v. 3, n.3, p. 147-161, dez. 1999.

- A Teoria de Organização Industrial e Economia dos Custos de Transação: linhas gerais do referencial analítico. In: FARINA, E. M. M. Q.; AZEVEDO, P. F; SAES, M. S. M. Competitividade: Mercado, Estado e Organizações. São Paulo: Singular, 1997. Cap. Introdução.

GIORDANO, S. R. The Importance of Socioenvironmental Certification in Agri-Chains. In: ZULBERSZTAJN, D.; OMTA, O. Advances in Supply Chaibn Analysys in Agri-Food Systems. São Paulo: Singular, 2009. p. 167-185.

HADDAD, P. R. A competitividade do agronegócio e o desenvolvimento regional no Brasil. Brasília: CNPQ/EMBRAPA, 1999.

IBGE - INSTITUTO BRASILEIRO DE GEOGRAFIA ESTATístICA. Censo Agropecuário. IBGE. Rio de Janeiro. 2006

MARCONI, M; LAKATOS, E. Metodologia do Trabalho Científico. $7^{\text {a }}$ ed.. São Paulo: Atlas, 2009. 
Flávio Braga de Almeida Gabriel, Daniel Amorim Souza Centurião, Caroline Andressa Welter, Grazielli Olimpia Viviani Pedroso da Silva

MATO GROSSO DO SUL. Zoneamento Ecológico-Econômico do Estado de Mato Grosso do Sul. Anexo I da Lei $n^{\circ}$. 3.839, de 28 de dezembro de 2009. Diário Oficial Estado de Mato Grosso do Sul. N ${ }^{\circ}$. 7.612 - Suplemento, Campo Grande-MS, 29 dez. 2009. p. 3-68.

NORTH, D. C. Institutions. The Journal of Economic Perspectives, v. 5, n.1, p. 97-112, 1991.

NORTH, D. C. Institutions, institutional change and economic performance. Cambridge: Cambridge University Press, 1990.

NORTH, D. C. Five propositios about institutional change. Ideas, 2003. Disponivel em: <https://ideas.repec.org/p/wpa/wuwpeh/9309001.html>. Acesso em: mar.2020.

REFLORE - ASSOCIAÇÃO SUL-MATO-GROSSENSE DE PRODUTORES E CONSUMIDORES DE FLORESTAS PLANTADAS. Plano Estadual para o Desenvolvimento Sustentável de Florestas Plantadas. Campo Grande, 2009.

SIGA - SISTEMA DE INFORMAÇÃO GEOGRÁFICA DO AGRONEGÓCIO. (2012). Áreas plantadas de eucalipto, pinos e estabelecimentos rurais com áreas destas culturas. 2012. Disponível em: <http://www.sigaweb.org/>. Acesso em: 20 mar. 2017.

SANTOS, M. Economia Espacial: Críticas e Alternativas. $2^{\text {a }}$ ed. São Paulo: Edusp, 2003.

SCHMIDT, V. et al. Estruturas de governança e os atributos das transações entre produtores de florestas plantadas e serrarias no município de Ribas do Rio Pardo/MS. In: Congresso da Sociedade Brasileira de Economia, Administração e Sociologia Rural - SOBER, 51, 2013, Belém. Anais... Disponível em: <http://sober.org.br/congresso2013/>. Acesso em: 15 ago. 2013.

VERGARA, S. C. Métodos de pesquisa em administração. São Paulo: Atlas, 2005.

WILLIAMSON, O. Comparative economic organization: the analysis of discrete structural alternatives. Administrative science quarterly, v. 36, n. 2, p. 269-296, 1991.

. The new institutional economics: taking stock, looking ahead. Journal of Economic Literature, v. 38, p. 595-613, set. 2000.

.The Theory os the Firm as Governance Structure: from Choice to Contract. Journal of Economic Perspectives, p. 171-195, summer 2002.

- Transaction-cost economics: the governance of contractual relations. Journal of Law and Economics, Chicago, v. 22, n. 2, p. 233-261, oct. 1979. 
ZYLBERSZTAJN, D. Economia das Organizações. In: ZYLBERSZTAJN, D.; NEVES, F. N. Gestão dos Negócios Agroalimentares. São Paulo: Pioneira, 2000. p. 23-38.

\section{ZYLBERSZTAJN, D; SCARE, R. F. Gestão da qualidade no agrobusiness: estudos e} casos. São Paulo: Atlas, 2003.

Flávio Braga de Almeida Gabriel. Professor Adjunto da Universidade Estadual do Oeste do Paraná. fbagabriel@gmail.com

Daniel Amorim Souza Centurião. Universidade Estadual do Oeste do Paraná - Toledo - PR - Brasil. dancenturiao@gmail.com

Caroline Andressa Welter. Universidade Estadual do Oeste do Paraná Toledo - PR - Brasil. carolweltero1@gmail.com

Grazielli Olimpia Viviani Pedroso da Silva. Universidade Estadual do Oeste do Paraná - Toledo - PR - Brasil. pedrosogra@gmail.com

Como citar: GABRIEL, Flávio Braga de Almeida et al. Estruturas de Governança e Atributos das Transações no Complexo Agroindustrial de Florestas Ribas do Rio Pardo (MS). Redes (St. Cruz Sul, Online), Santa Cruz do Sul, v. 25, n. 2, p. 762-781, abr. 2020. ISSN 1982-6745. Disponível em: https://online.unisc.br/seer/index.php/redes/article/view/12348 Acesso em: 22 maio 2020. doi: https://doi.org/10.17058/redes.v25i2.12348

\section{CONTRIBUIÇÃO DE CADA AUTOR}

a. Fundamentação teórico-conceitual e problematização: Flávio Braga de Almeida Gabriel, Daniel Amorim Souza Centurião, Caroline Andressa Welter, Grazielli Olimpia Viviani Pedroso da Silva.

b. Pesquisa de dados e análise estatística: Flávio Braga de Almeida Gabriel, Daniel Amorim Souza Centurião, Caroline Andressa Welter, Grazielli Olimpia Viviani Pedroso da Silva.

c. Elaboração de figuras e tabelas: Flávio Braga de Almeida Gabriel, Daniel Amorim Souza Centurião, Caroline Andressa Welter, Grazielli Olimpia Viviani Pedroso da Silva

d. Fotos: não se aplica.

e. Elaboração e redação do texto: Flávio Braga de Almeida Gabriel, Daniel Amorim Souza Centurião, Caroline Andressa Welter, Grazielli Olimpia Viviani Pedroso da Silva

f. Seleção das referências bibliográficas: Flávio Braga de Almeida Gabriel, Daniel Amorim Souza Centurião, Caroline Andressa Welter, Grazielli Olimpia Viviani Pedroso da Silva.

Fontes de financiamento: $O$ presente trabalho foi realizado com apoio da Coordenação de Aperfeiçoamento de Pessoal de Nível Superior - Brasil (CAPES) - Código de Financiamento 001. 